\title{
PLUS JAMAIS ESCLAVES! DE L'INSOUMISSION À LA RÉVOLTE, LE GRAN RÉCIT D’UNE EMANCIPATION (1492-1838)
}

Aline Helg, Plus jamais esclaves! De l'insoumission à la révolte, le gran récit d'une emancipation (1492-1838), París, Éditions La Découverte, 2016, 419 pp.

No se puede negar la gran valía de los trabajos de Seymour Drescher sobre el abolicionismo. Sus múltiples artículos y sus diversos libros han servido para mejorar y ampliar nuestro conocimiento sobre las formas de oposición a la esclavitud, empezando por su libro seminal Econocide. British slavery in the Era of Abolition, publicado hace más de cuarenta años. En aquella monografía Drescher daba completamente la vuelta a uno de los argumentos centrales de Eric Williams en su trabajo Capitalism E Slavery, un argumento según el cual el final de la esclavitud en las colonias británicas se había dado por que dicha institución había pasado a ser obsoleta (o sea, poco rentable), en términos económicos. Drescher puso de relieve, por el contrario, que al abolir la esclavitud en sus colonias, los británicos habían cometido un verdadero «econocidio» pues la explotación del trabajo esclavo seguía siendo remunerador. Si, según Drescher, no era en la economía donde había que buscar las razones del abolicionismo británico, entonces..., ¿dónde había que buscarlas? Pues en el mundo de las ideas. Unas ideas que movieron el mundo Atlántico a caballo de los siglos XVIII y XIX.

Los trabajos de Drescher pusieron, entonces, en valor dos tesis principales: (1) el abolicionismo fue un movimiento impulsado fundamentalmente por razones ideológicas, morales; y (2) en el caso británico había que ir más allá del estudio de los «santos abolicionistas» para analizar la existencia de un verdadero y masivo movimiento popular que conseguiría, finalmente, colocar la cuestión de la abolición en el centro de la agenda política del país. El principal problema de los argumentos de Seymour Drescher es que en sus trabajos no ha tenido en cuenta la labor de los propios esclavos en la erosión y, finalmente, en la abolición de la institución de la esclavitud. En sus libros, los esclavos (es decir, los hombres y mujeres que sufrieron en sus propias carnes el fenómeno de la esclavitud) no aparecen como sujetos de sus análisis. Están completamente ausentes. Conforman una variable exógena. En los textos de Drescher lo esclavos no aparecen como sujetos activos, capaces de construir sus propias realidades y de modificar las sociedades en las que vivieron, sino que aparecen como meros objetos en el debate que enfrentó a defensores y a detractores de la esclavitud. 
En ese sentido, el magnífico libro de Aline Helg viene a poner de relieve hasta qué punto el final de la esclavitud en las Américas fue el resultado de un largo proceso que no puede entenderse, en toda su extensión y complejidad, si no es teniendo en cuenta la lucha de los propios esclavos contra una institución que los oprimía a todos los niveles. Cabe entender este libro como la obra de madurez de una gran historiadora, que ha publicado diferentes libros sobre temáticas parecidas o, al menos, relacionadas. El primer libro de Helg, editado por la prestigiosa University of North Carolina Press en 1995 llevaba por título Our Rightful Share: The Afro-Cuban Struggle for Equality, 1886-1912; un libro centrado en el período que va del final de la esclavitud en Cuba hasta la masacre de los simpatizantes del Partido Independiente de Color en el que puso de relieve las dificultades para construir una democracia racial en la nueva República de Cuba (un fenómeno que acabaría también visitando años después, aunque desde una óptica diferente, Alejandro de la Fuente en su magnífica monografía $A$ Nation for $A l l$ ). Tras haberse dedicado unos años al estudio de los afrocolombianos (sin dejar de tener presente el camino hacia la igualdad o la libertad), la profesora Aline Helg ha publicado (esta vez en francés) un estupendo trabajo en el que transita por los múltiples episodios registrados en tierras americanas protagonizados por esclavos con la voluntad de ofrecer un análisis de conjunto de la lucha por la libertad de los africanos y de los afrodescendientes en el Nuevo Mundo.

Una de las principales virtudes del libro radica en su capacidad por incorporar, en un único eje discursivo, un amplísimo conjunto de episodios (algunos de alcance local y otros de alcance global), acontecidos en lugares diferentes y con diversa cronología, y por ofrecer después una interpretación inteligente sobre dichos episodios. Más allá de los acontecimientos concretos que se analizan y del valor que hayan podido tener para las diferentes historias locales, regionales o nacionales, el libro de Helg nació con una clara voluntad de cubrir el conjunto del continente americano. Y de hacerlo, además, en una amplia secuencia cronológica de más de trescientos años. Al hacerlo (y de forma exitosa, además) muestra dicha autora su vasto conocimiento de una extensa literatura, sobre la acaba que construyendo su relato.

El planteamiento del libro presenta una ordenación cronológica de los capítulos combinada con una aproximación temática. Dedica su autora el primero de los diez epígrafes (que constituye, por sí solo, la primera de las cuatro partes de la monografía) a presentar, de una forma muy general, el fenómeno del tráfico de esclavos y de la esclavitud en el conjunto del continente americano, entre los siglos XVI y XIX. Le siguen a continuación las otras tres partes del volumen, que vienen a cubrir tres sucesivos períodos cronológicos. El primero empieza con la llegada colombina a América y termina con el fin de la Guerra de los Siete Años, en 1763. Así, en tres sucesivos capítulos analiza las diferentes vías utilizadas por los esclavos para escapar de la esclavitud, tanto las ilegales (tal que el cimarronaje y las conspiraciones y revueltas) como las legales (la autocompra de la libertad o el alistamiento en tropas militares). La segunda parte la titula Helg «la era de las independencias» y en ella analiza, en cuatro capítulos sucesivos, el rol que jugaron los esclavos en las independencias de los Estados Unidos, primero, de Haití, después, y de la América hispana, en último lugar). 
Es en este apartado donde se hace evidente una de las grandes deficiencias del libro: la práctica ausencia de Brasil. No hubo, ciertamente, guerra de independencia en Brasil pero no hubiese estado de más incorporar en esta parte algún epígrafe con reflexiones sobre los vínculos entre la institución de la esclavitud y la forma concreta de la independencia de Brasil, respecto a Portugal. Al fin y al cabo, como bien demostró en su día Luiz Felipe de Alencastro, la institución de la esclavitud fue la argamasa que permitió la unidad de la colonia (frente a la disgregación en diferentes estados que acabaría caracterizando a la América española) y luego el mantenimiento del nuevo Brasil bajo la forma de un Imperio. No es casual que coincidan prácticamente las fechas de la abolición de la esclavitud en Brasil (1888) y del fin del Imperio y de la proclamación de la República (1889). Otorgar un mayor peso al Brasil portugués (en esa parte y en todo el libro) hubiese sido ciertamente deseable.

En la cuarta y última parte de la monografía, titulada «Entre esclavismo y abolicionismo» Helg analiza el período que va desde 1800 hasta la abolición efectiva de la esclavitud en las colonias británicas (tras el final del proceso de «aprendizaje), reflexionando sobre las diferentes revueltas que se dieron en esas casi cuatro décadas. Estamos hablando de ese período que Dale Tomich definió como «la segunda esclavitud», a partir de una óptica tan útil como sugerente para este tipo de estudios y que, sin embargo, la autora desconoce (o no tiene en cuenta). Sorprende también, hasta cierto punto, la cronología final de su trabajo (1838). Al hacerlo así, se fija sobre todo la autora en el caso británico pero no quiere tener en consideración que la esclavitud se mantuvo todavía vigente en algunos lugares de América durante otros cuarenta años más: en las colonias francesas de América (hasta 1848), en las colonias holandesas (hasta 1863), en los Estados Unidos de América (hasta 1865) en Puerto Rico y Cuba (hasta 1873 y 1886, respectivamente) y en Brasil (hasta 1888). Por no hablar de la esclavitud en las nuevas repúblicas hispanoamericanas (vigente, en buena parte de las mismas, hasta la década de 1850).

Sea como fuere, esos aspectos no deben desmerecer el inmenso esfuerzo y trabajo llevado a cabo por Aline Helg, quien ha tenido la capacidad de recoger y de dar sentido, en un único volumen, los múltiples y diversos esfuerzos de los esclavos africanos y afrodescencientes por salir de la esclavitud en las Américas. Ahora que está tan de moda razonar sobre la agency de los propios esclavos en diferentes aspectos de su realidad, una monografía como la de Helg aporta múltiples elementos interesantes para dicha reflexión. Y aunque el valor del libro va mucho más allá, no quiero dejar de señalar que aporta un conocimiento necesario (complementario a los enfoques de Drescher) sobre el fenómeno del abolicionismo.

Martín Rodrigo y Alharilla

GRIMSE-UPF 